\title{
A NÃO EQUIPARAÇÃO DO TRÁFICO DE DROGAS PRIVILEGIADO A CRIME HEDIONDO: UMA ANÁLISE COMPORTAMENTAL
}

Julio Cesar Aguiar ${ }^{1}$

Tiago Gomide Alves ${ }^{2}$

Benjamin Miranda Tabak ${ }^{3}$

\section{Resumo}

O presente artigo jurídico pretende fazer uma análise comportamental do entendimento do Supremo Tribunal Federal adotado no julgamento do HC 118533/MS de que o chamado tráfico privilegiado não pode ser equiparado aos crimes hediondos, discutindo cientificamente se a decisão do Supremo Tribunal Federal contribuirá ou não para a redução do número de pessoas presas no país.

Palavras-chave: Análise Comportamental; Tráfico De Drogas; Crime Hediondo; Encarceramento.

\section{INTRODUÇÃO}

O tráfico e o consumo de drogas são alguns dos maiores desafios a serem enfrentados, não só pelo Brasil, mas também por diversos outros países, tanto assim que já na década de 1960, mais especificamente em 1961, a Organização das Nações Unidas - ONU - estabeleceu a Convenção Única Sobre Entorpecentes ${ }^{4}$. A venda e o consumo causam profunda preocupação, uma vez que não dizem respeito apenas a questões envolvendo saúde pública, como também afeta a segurança pública. Não é novidade que o tráfico ilícito de entorpecentes serve

\footnotetext{
${ }^{1}$ Professor doutor do Mestrado em Direito da UCB. E-mail: juliocesar.deaguiar@gmail.com

${ }^{2}$ Mestrando UCB.E-mail: thiagogalves@hotmail.com

3 Professor da Escola de Políticas Públicas e Governo da Fundação Getúlio Vargas (FGV/EPPG). E-mail: benjaminm.tabak@gmail.com

${ }^{4}$ Promulgada no Brasil pelo Decreto no 54.216, de 27 de agosto de 1964.
} 
como pano de fundo para a prática de diversos outros delitos cometidos tanto pelos próprios traficantes, no enfrentamento com as forças policiais, nas disputas por pontos de venda de drogas com traficantes rivais ou contra usuários que não pagam pela droga consumida, como pelos usuários, que muitas vezes recorrem à prática de crimes para poderem sustentar o vício.

O Poder Constituinte de 1988, atento ao problema, também mostrou especial preocupação com o tráfico de drogas. De início, é possível constatar a presença do que Feldens (2008, p.72) chama de "mandado constitucional de penalização" ou "mandado constitucional de criminalização" em relação ao tráfico ilícito de entorpecentes e de drogas afins. Esse mandado de criminalização vincula, irremediavelmente, o legislador infraconstitucional, de tal modo que ele não pode deixar de considerar crime uma conduta (qual seja, a traficância de drogas) que a Constituição determinou que fosse tratada como tal. Segundo Feldens (2008) o mandado constitucional de criminalização também gera uma obrigação para o Poder Judiciário, em especial para o Tribunal Constitucional, ao qual incumbe analisar a legitimidade constitucional de uma lei penal que possa ser qualificada como "excedente" ou, igualmente, como "deficiente" na tutela dos bens jurídicos escolhidos pelo Poder Constituinte.

O mandado de criminalização ao qual aqui se refere deu-se de expressamente no artigo $5^{\circ}$, inciso XLIII da Constituição Federal de 1988, segundo o qual “a lei considerará crimes inafiançáveis e insuscetíveis de graça e anistia a prática de tortura, o tráfico ilícito de entorpecentes e drogas afins, o terrorismo e os definidos como crimes hediondos, por eles respondendo os mandantes, os executores e os que, podendo evitá-los, se omitirem”.

A partir da leitura do inciso XLIII acima transcrito é possível perceber que a preocupação do Constituinte, ou a vontade constitucional de combater severamente o tráfico de entorpecentes, não se limitou com o simples mandamento de criminalização. Ao contrário, avançou ao equiparar o tráfico ilícito de entorpecentes e drogas afins aos crimes hediondos e, ainda, determinou que tal crime fosse inafiançável e insuscetível de graça e de anistia. De maneira ainda mais incisiva, o Poder Constituinte, no inciso L de do artigo $5^{\circ}$ da Carta Magna Brasileira, deu ao tráfico ilícito de entorpecentes e de drogas afins um tratamento especial, diverso de qualquer outro crime, ao estabelecer que o brasileiro naturalizado será extraditado, na forma da lei, caso cometa o crime de tráfico de drogas, mesmo que a conduta tenha ocorrido após a naturalização. Isso significa dizer que se um brasileiro naturalizado cometer, no país, mesmo após sua naturalização, um ato de terrorismo não poderá ser extraditado, mas ser for condenado por tráfico de drogas, a extradição ocorrerá nos termos da lei.

Por fim, também de maneira expressa, a Constituição Federal de 1988 voltou a tratar do tráfico de entorpecentes e de drogas afins no artigo 243, ao estabelecer a expropriação de terras rurais e urbanas que venham a ser utilizadas para a plantação de droga, bem como o confisco de "todo e qualquer bem de valor econômico apreendido em decorrência do tráfico ilícito de entorpecentes e drogas afins". 
As normas constitucionais acima referidas refletem o dever de proteção identificado pelo Poder Constituinte, traduzindo verdadeiros mandados de criminalização expressos, de observância obrigatória.

Em cumprimento à necessária obediência à Constituição, o Congresso Nacional aprovou duas leis federais que dão concretude e efetividade ao mandamento constitucional: a Lei ${ }^{\circ} 11.343 / 2006$ e a Lei no 8.072/1990, conhecidas, respectivamente, como Lei de Tráfico de Drogas e Lei dos Crimes Hediondos.

No $₫ 4^{\circ}$ do artigo 33 da atual Lei de Tráfico de Drogas, está prevista a causa de diminuição de pena que ficou conhecida como "tráfico privilegiado" 5 , objeto de discussão neste trabalho. Estabelece o mencionado $₫ 4^{\circ}$ que nos delitos definidos no caput e no $₫ 1^{\text {o }}$ do próprio artigo 33 da Lei no $11.343 / 2006$ as penas poderão ser reduzidas de um sexto a dois terços, desde que o agente seja primário, de bons antecedentes, não se dedique às atividades criminosas nem integre organização criminosa. Na hipótese de incidência da mencionada causa de diminuição de pena é que se estará diante do que ficou conhecido como tráfico privilegiado. Não incidindo a causa de diminuição de pena do $\$ 4^{\circ}$, será "tráfico de drogas comum".

Também em sintonia com a Constituição Federal, a Lei no 8.072/90 define os crimes hediondos e, no artigo $2^{\circ}$, dá a esses e ao tráfico ilícito de entorpecentes e de drogas afins um tratamento equiparado.

No que diz respeito ao tráfico privilegiado, por se tratar, na verdade, de uma causa de diminuição de pena e não de um tipo penal autônomo, os Tribunais Superiores sempre mantiveram o entendimento de ser ele, também, equiparado a crime hediondo. Nesse sentido, o Superior Tribunal de Justiça (STJ) editou a Súmula nº 512, cujo enunciado reza que "a aplicação da causa de diminuição de pena prevista no artigo 33 não afasta a hediondez do crime de tráfico de drogas". Da mesma forma, desde o advento da Lei no 11.343/2006 as duas Turmas do Supremo Tribunal Federal - STF - sempre entenderam que o tráfico privilegiado era um crime de natureza hedionda.

Contudo, em 2016, o Supremo Tribunal Federal, ao julgar o HC 118533/MS, ${ }^{6}$ modificou seu posicionamento e decidiu que o tráfico privilegiado não pode ser equiparado a crimes hediondos, em uma mudança que, inclusive, motivou o cancelamento da referida Súmula no 512 do Superior Tribunal de Justiça.

Portanto, durante uma década (desde a promulgação da Lei no 11.343/2006 até o julgamento do HC 118533/MS em 2016) o STF não questionou ou, em outras palavras, nunca afastou a hediondez do tráfico privilegiado. Cabe ressaltar que nesse lapso temporal de dez anos não houve nenhuma grande mudança constitucional ou no ordenamento jurídico como um todo, aqui se tomando o termo ordenamento jurídico do ponto de vista estritamente dogmático, positivista, como sendo o conjunto de normas do um Estado estabelecidas

\footnotetext{
${ }^{5} \mathrm{O}$ termo" tráfico privilegiado" foi colocado entre aspas de maneira proposital, para indicar que não se trata de crime autônomo, mas de simples causa de diminuição de pena do crime previsto no caput do artigo 33 da Lei no 11.343/2006. Feita essa ressalva, as demais referências ao "tráfico privilegiado" contidas neste texto passarão a ser feitas sem o uso das aspas.
} 
em lei em seu sentido amplo (BOBBIO, 2008, p.28).

Se a lei não mudou, qual seria a justificativa para verdadeira guinada ocorrida no entendimento do STF? A resposta parece estar em uma mudança ocorrida não no conjunto de leis editadas pelo Estado, mas na própria realidade social, notadamente no que diz respeito ao aumento significativo da população carcerária no Brasil ${ }^{7}$.

Da leitura do acórdão do HC 118553/MS é possível perceber que a preocupação maior dos Ministros do STF é com o que se convencionou chamar de "superencarceramento" ou mesmo "hiperencarceramento". Os Ministros Barroso, Carmen Lúcia e Lewandowski inclusive fizeram expressa referência ao contingente de pessoas presas, até mesmo fazendo referências a estatísticas. $\mathrm{O}$ acórdão permite concluir ainda que, sob a fundamentação jurídico-dogmática apresentada pelos votos vencedores, havia, no fundo, a vontade de implementar uma política penitenciária de desencarceramento ${ }^{8}$.

Mas nenhuma análise jurídica do ponto de vista exclusivamente dogmático será suficiente para se discutir eventual acerto ou desacerto da decisão do STF se não se atentar para os reais motivos que levaram à Suprema Corte Brasileira a mudar sua jurisprudência. Vale dizer que não se pode perder de vista que o Supremo Tribunal Federal está mais preocupado com a quantidade de presos no Brasil, do que, por exemplo, com a força normativa da Constituição (HESSE, 1991) ou com qualquer outra teoria jurídico-dogmática.

Fazendo a diferença entre as razões de decidir e os fundamentos periféricos da decisão utilizada na common law, no julgamento do HC 118533/MS o que parece ser a obter dicta, na realidade, é a ratio decidendi.

Restou evidente na decisão o objetivo de implementar-se uma política pública. A começar pelo caso concreto posto em julgamento em que os pacientes do HC 118533/MS foram flagrados transportando 772 quilos de maconha, indicando, objetivamente, que não se tratava de tráfico privilegiado.

Pois bem, se a análise jurídico-dogmática nos parece insuficiente para perquirir de maneira aprofundada e científica eventual acerto ou desacerto da decisão do STF de que o tráfico privilegiado não é hediondo, torna

\footnotetext{
${ }^{6}$ HC 118533. Processo Eletrônico DJe-199. Divulg 16-09-2016, Public 19-09-2016.

${ }^{7} \mathrm{O}$ aumento da população carcerária no Brasil ao longo dos anos é um fato inegável sendo que, de acordo com dados do Conselho Nacional de Justiça - CNJ, a população nacional de presos no sistema no ano de 2014 era de 563.526. Somados aos presos em prisão domiciliar o total era de 711.463. Ainda de acordo com dados do CNJ, o número de presos no Brasil em janeiro de 2017 era de 654.372. Contudo, no site do CNJ não há menção se nesse número estão incluídos ou não os presos em regime domiciliar. $\mathrm{O}$ fato de se admitir aqui que houve expressivo aumento da população carcerária não significa, todavia, que se está de antemão concordando que exista um problema de superencarceramento, pois a nosso sentir tal constatação demandaria no mínimo uma análise sobre a necessidade das prisões decretadas, sobre a proporcionalidade entre a quantidade de presos e o número de pessoas que vivem no país, sobre a proporcionalidade de pessoas presas e a quantidade de crimes praticados no país e, por fim, uma análise comparativa de dados com o número de presos versus número de crimes em outros países. Tal análise, por ser complexa, extrapola os objetivos desse trabalho.

${ }^{8}$ Como não se pretende discutir, neste trabalho, o ativismo judicial, não se vai aqui questionar eventuais limites ou legitimidade do Poder Judiciário na escolha e na efetivação de políticas públicas. Fica o registro da razão evidente da decisão do STF, que não foi de natureza eminentemente jurídica ou, pelo menos, não foi exclusivamente jurídica (na acepção positivista da palavra), mas política e pragmática.
} 
necessária a utilização de outra ou outras espécies de análises, as quais podem ser feitas em conjunto com a análise jurídico-dogmática (de verificar eventual desrespeito à hierarquia das normas ou possível conflito ainda que aparente entre normas igualmente válidas e vigentes) ou separadamente.

Nessa perspectiva, o presente trabalho pretende fazer uma análise comportamental da decisão tomada pelo Supremo Tribunal Federal no HC 118533/MS que, mudando seu posicionamento anterior, passou a entender que o crime de tráfico privilegiado não pode ser equiparado a hediondo. A decisão tomada pelo Supremo Tribunal Federal constitui-se verdadeiramente em novo regramento do chamado tráfico privilegiado (art. 33, $\ 4^{4}$, da Lei Federal no 11.343/2006), possuindo, assim, aptidão para influenciar o comportamento de todos que estão sob a jurisdição da Suprema Corte Brasileira. Isso já justificaria uma análise comportamental da decisão tomada.

Ademais, como deixam claros alguns Ministros em seus votos, o objetivo maior da mudança de entendimento foi a implementação de uma política pública de desencarceramento, sendo que a partir de um modelo analítico-comportamental será possível discutir a maior ou menor probabilidade de que seja atingida a meta social estabelecida pelo Supremo Tribunal Federal, qual seja, a redução maciça do número de presos no Brasil.

\section{ANÁLISE COMPORTAMENTAL DO DIREITO: IDEIAS BÁSICAS E VARIÁVEIS DO COMPORTAMENTO HUMANO}

A análise comportamental do Direito busca fazer uma nova abordagem científica do Direito e encontra seu fundamento em uma versão do que ficou conhecido como behaviorismo radical, o qual foi criado pelo psicólogo norte-americano Skinner na década de 1930 (AGUIAR \& TABAK, 2016, p. 15-25). Para a análise comportamental, o Direito é um sistema de padrões comportamentais entrelaçados que visam o controle punitivo dos comportamentos considerados socialmente indesejáveis. Dessa forma, as várias possibilidades do comportamento humano são selecionadas por contingências que visam, ao fim e ao cabo, garantir a sobrevivência e a reprodução do grupo social com um todo (SKINNER, 1981, p.502).

O modelo analítico-comportamental, com vistas ao estudo científico do Direito, busca explicar o comportamento humano a partir de quatro variáveis, quais sejam, o padrão comportamental operante, o contexto, o estado motivacional e as consequências, sendo essas últimas divididas em reforços ou recompensas e punições (AGUIAR, 2017, p.31-32).

O padrão comportamental operante é a variável dependente (por depender das outras três variáveis) do modelo analítico-comportamental, sendo uma unidade de análise do repertório comportamental de um 
indivíduo, o qual se estende no tempo e no espaço (AGUIAR \& TABAK, 2016, p. 16). Para exemplificar, vamos imaginar que um indivíduo dentro de seu repertório comportamental (dormir, almoçar, trabalhar, assistir televisão, fazer compras) adote o padrão comportamental operante de jogar futebol com os amigos no sábado, oportunidade em que pratica uma atividade física e desfruta momentos agradáveis ao lado dos amigos, diminuindo a solidão de morar sozinho. Jogar futebol será uma unidade separada dos demais comportamentos que constituem o repertório comportamental do indivíduo, unidade essa que servirá para a análise comportamental. Portanto será considerado um padrão comportamental operante jogar futebol ao longo de uma unidade temporal qualquer (semana, mês, ano, por exemplo). O padrão comportamental operante é dimensionado por sua frequência e é com base nessa frequência que se pode prever a probabilidade de ocorrência futura de determinado padrão comportamental operante, dados o mesmo estado motivacional (necessidade de praticar esporte e solidão de morar sozinho) e o mesmo contexto (ser sábado), bem como mantida estável as consequências reforçadoras ou punitivas (praticar atividade física e desfrutar de momentos agradáveis ao lado dos amigos).

O contexto é a variável independente que sinaliza para o indivíduo a maior ou menor probabilidade de ocorrência da consequência reforçadora, caso adotado o padrão comportamental operante. No nosso exemplo, ser sábado é um elemento contextual que sinaliza que os amigos estarão de folga e participarão do futebol, o que seria difícil em um dia útil. Dois elementos importantes que dizem respeito ao contexto é a generalização e a discriminação (AGUIAR \& TABAK, 2016, p. 17). A generalização estende características de um contexto a outros semelhantes (se os amigos podem jogar futebol no sábado isso pode indicar que também estarão disponíveis em um feriado). A discriminação indica que apesar de o contexto ser o mesmo outro fator tende a não tornar o padrão comportamental tão compensador. $\mathrm{O}$ fato de estar chovendo no sábado pode indicar a ausência da maioria dos amigos no futebol e aumentar as chances de lesão muscular, por exemplo. Assim a chuva servirá como discriminante do contexto (sábado).

O estado motivacional é a variável independente que torna momentaneamente mais ou menos reforçadora uma consequência determinada, o que torna mais provável a repetição do padrão comportamental operante. (AGUIAR \& TABAK, 2016, p. 18). Os estados motivacionais estão ligados às privações (fome, sede, solidão) e às estimulações aversivas (dor, excesso de calor ou de frio, por exemplo). Assim, se o indivíduo está sentido falta da prática de esporte ou se está se sentido só, esses estados motivacionais tornam mais prováveis que ele vá jogar futebol com os amigos no sábado. Por outro lado, se ele já tiver praticado bastante esporte ao longo da semana ou já tiver companhia para o final de semana isso torna menos reforçador as consequências praticar atividade esportiva e desfrutar a convivência com os amigos de futebol.

As consequências (reforços ou punições) são as variáveis independentes que determinam a vol.11, n. 04, Rio de Janeiro, 2018.pp. 3371-3392 
probabilidade de ocorrer determinado padrão comportamental operante. Os reforços (possibilidade de praticar esportes e de encontrar os amigos) fazem aumentar a probabilidade de ocorrência do padrão comportamental operante (jogar bola) e as punições (risco de lesões musculares, por exemplo) tendem a tornar o comportamento menos frequente ou até mesmo cessá-lo. Essa ligação causal entre o padrão comportamental operante e as consequências (reforçadoras ou punitivas) recebe o nome de "contingência comportamental" (AGUIAR \& TABAK, 2016, p. 19).

Como é possível perceber, variações quantitativas ou qualitativas nas variáveis independentes (contexto, estado motivacional e consequências) irão interferir na probabilidade de ocorrência do padrão comportamental operante. Assim, por exemplo, se a quantidade de lesões musculares ou a gravidade delas aumentar substancialmente (consequência punitiva) isso tenderá a interferir na frequência em que o indivíduo adotará o padrão comportamental operante jogar futebol com os amigos no sábado, apesar de continuar gostando de jogar futebol, de sentir necessidade de praticar esporte e de ainda apreciar o convício com os amigos.

Em outras palavras, de acordo com o modelo analítico-comportamental a punição a determinados comportamentos tende a reduzir a repetição daquele comportamento. Nessa perspectiva, o sistema jurídico nada mais é do que um sistema estatal especializado na punição de comportamentos considerados indesejáveis em uma dada sociedade, visando à diminuição desses comportamentos a níveis mínimos (AGUIAR, 2013, p. 180).

É de se atentar que as consequências punitivas sempre pressupõem consequências reforçadoras responsáveis pela manutenção do padrão comportamental operante, de tal forma que consequências punitivas e reforçadoras atuam de maneira sobreposta. Assim, as lesões musculares para funcionarem como punidoras do padrão comportamental jogar futebol pressupõem uma consequência reforçadora como, por exemplo, praticar atividade física e poder encontrar os amigos (AGUIAR, 2017, p. 37). De maneira idêntica, a pena pela prática do crime (consequência punitiva) pressupõe o lucro, a vantagem ou a satisfação obtidos com a prática do delito (consequência reforçadora). Por essa razão, para que a consequência punitiva seja capaz de reduzir a incidência no repertório do indivíduo de comportamentos considerados socialmente indesejáveis ela deve ser de tal gravidade que suplante os benefícios que costumam advir daquele comportamento, ou seja, as consequências reforçadoras não podem compensar quando comparadas às consequências punitivas.

Skinner (1953, p.340) acrescenta que para que o poder de dissuasão da aplicação de sanções seja socialmente útil ele tem que necessariamente ir além do indivíduo que por praticar o delito deve ser por isso punido. Logo, aqui adotando a teoria do direito, a punição deve envolver tanto a prevenção especial que recai sobre o autor do delito quanto a prevenção especial, que abarca terceiros que possuem a propensão a cometer crimes, a qual é diminuída pela aplicação de sanções a outros indivíduos, o que lhes serve de exemplo.

De outro lado, uma sanção excessiva ou desproporcional tende a levar uma aversão à própria sanção, o 
que tende a diminuir a sua aplicação e, consequentemente, a torna ineficaz para a diminuição do comportamento considerado socialmente indesejável (AGUIAR, 2017, p. 110). Imagine-se, por exemplo, que fosse prevista pena de morte ou de reclusão de 30 (trinta) anos para o crime de furto, o qual é praticado sem violência ou grave ameaça. Haveria uma tendência de que tais penas fossem raramente aplicadas ante a sua desproporcionalidade, o que implicaria em dizer que o próprio furto seria raramente punido.

Explicitadas as ideias básicas da análise comportamental e as variáveis do comportamento (padrão comportamental operante, consequências, contexto e estado motivacional) passaremos a seguir a discutir a análise comportamental da regra jurídica.

\section{ANÁLISE COMPORTAMENTAL DA REGRA JURÍDICA}

As regras para a análise comportamental podem ser definidas como sendo "padrões comportamentais verbais cuja probabilidade de ocorrência depende da sua capacidade de alterar a frequência de determinado padrão comportamental no repertório de dado indivíduo ou grupo de indivíduos" (AGUIAR, 2017 p. 132-133). No que dizem respeito às regras elas têm por objetivo o controle coercitivo de comportamentos considerados politicamente (pelo Estado) como prejudiciais à sociedade, vale dizer: elas buscam alterar o padrão comportamental do destinatário por meio da sanção ou da ameaça de sanção estatal. A regra jurídica deve "obter o estado de coisas favorável à sobrevivência, reprodução e bem-estar da sociedade (...)” (AGUIAR, 2017, p.135).

Para que se possa fazer a análise comportamental de uma regra ela é subdividida em três componentes, quais sejam: 1- contingência jurídica; 2- meta social e 3- premissas comportamentais relevantes.

Se, conforme explicado no subitem anterior, a "contingência comportamental" é a ligação causal entre o padrão comportamental operante e as consequências (reforçadoras ou punitivas) a "contingência jurídica" é a relação contingente entre a conduta que se busca controlar por meio da aplicação de sanção e a sanção propriamente dita. A contingência jurídica é, portanto, a relação contingente entre o crime e a respectiva sanção. No caso do caso do crime de homicídio é a relação entre a conduta "matar alguém" e a sanção "reclusão, de seis a vinte anos".

A meta social é o estado de coisas que a imposição da contingência jurídica visa atingir, ou seja, é o estado de coisas tido como socialmente desejável e que depende direta ou indiretamente da instituição da contingência jurídica. As metas sociais podem ser imediatas ou mediatas (AGUIAR, 2017, p. 140-141). Para melhor compreensão iremos exemplificar. A contingência jurídica (relação entre o crime e a pena) estabelecida no crime de homicídio visa à diminuição do comportamento "matar alguém". A meta social imediata de tal regra jurídica é diminuir o máximo possível o comportamento operante de matar outra pessoa, protegendo-se a vida. Já no crime 
de tráfico de drogas a meta social a ser atingida é mediata, pois o que a regra pretende não é evitar que as pessoas tenham momentos de embriaguez com o uso dos entorpecentes, mas sim evitar que este uso recreativo ou abusivo traga problemas para a saúde pública e de aumento de criminalidade - decorrente da disputa por ponto de vendas entre traficantes ou necessidade dos usuários de obterem dinheiro para sustentar o vício, por exemplo.

As premissas comportamentais relevantes são as duas relações causais fundamentais pressupostas da regra jurídica (AGUIAR, 2016, p. 23). A primeira delas é a relação causal entre a imposição da sanção (normalmente a punição) e a diminuição ou aumento da conduta objeto da regra. É no exemplo acima citado, a relação entre a imposição da pena de reclusão de seis a vinte anos e a diminuição da frequência da conduta "matar alguém". A segunda é a relação causal entre a diminuição ou aumento da conduta e a obtenção da meta social, ou seja, é a relação entre a diminuição do comportamento "matar alguém" e a obtenção da meta social "paz pública/proteção da vida”.

Logo, a análise comportamental nos leva a pesquisar se a meta social de determinada regra jurídica está sendo ou se será alcançada com a instituição daquela determinada regra e mais: exige do aplicador da lei que questione se as premissas comportamentais relevantes e que foram adotadas para a instituição da regra são ou não verdadeiras.

No caso da decisão do Supremo Tribunal Federal que é objeto desse trabalho, a sua análise comportamental servirá para compreender cientificamente se a não equiparação do tráfico de drogas aos crimes hediondos servirá a um só tempo para atingir a metas sociais de proteção da saúde e da segurança pública e de desencarceramento e ainda para se questionar se as premissas comportamentais relevantes levadas em consideração pela Corte Suprema brasileira são ou não verdadeiras.

4. Análise comportamental da não equiparação do tráfico privilegiado a crime hediondo

Para que seja possível a realização da análise comportamental é preciso de antemão ter em mente que a decisão do Supremo Tribunal Federal de que o chamado tráfico privilegiado não pode ser equiparado aos crimes hediondos significa indiscutivelmente um abrandamento da punição. Como consequência imediata pode se citar a alteração do sistema de progressão de regime de pena, pois se deixa de exigir o cumprimento de $2 / 5$ (dois quintos) da pena previsto na lei dos crimes hediondos ${ }^{9}$, passando-se a exigir que o condenado cumpra apenas $1 / 6$ (um sexto) da pena para que possa progredir de regime ${ }^{10}$, ou seja, passar do regime semiaberto para o regime aberto, por exemplo. No caso de reincidência no tráfico de drogas a alteração é ainda mais profunda, passando de 3/5 (três quintos) para apenas 1/6 (um sexto). Portanto, antes da decisão do Supremo Tribunal Federal no HC 118533/MS o indivíduo condenado por tráfico de drogas (privilegiado ou não) que reincidisse, ou seja, que

\footnotetext{
${ }^{9}$ Art. 20, $\$ 2^{\circ}$, da Le Federal no 8.072/90

${ }^{10}$ Conforme dispõe o artigo 112 da Lei de Execução Penal, Lei Federal no 7.210/84.
} 
praticasse um segundo tráfico de drogas, teria que cumprir $3 / 5$ de sua pena para progredir de regime. Com o novo entendimento do Supremo Tribunal Federal, se no primeiro crime o indivíduo foi condenado por tráfico privilegiado, no segundo tráfico de drogas (seja ele privilegiado ou não) a progressão de regime será de apenas 1/6 da pena. A decisão da Suprema Corte brasileira ainda torna certa a possibilidade de o condenado por tráfico privilegiado ter direito a indulto, tendo em vista que há grande discussão sobre a possibilidade ou não de indulto para crimes hediondos, questão essa que está sendo objeto de julgamento pelo próprio Supremo Tribunal Federal em Ação Direta de Inconstitucionalidade (ADI 5343), ainda sem decisão.

A decisão tomada pelo Supremo Tribunal Federal possui o condão de influenciar o comportamento de todos aqueles que estejam no Brasil sob a jurisdição daquele tribunal, pois a nova regra de que o tráfico privilegiado não é equiparado a crime hediondo valerá para todos.

Partindo do modelo analítico-comportamental é possível dizer, então, que a consequência (punitiva) do padrão comportamental operante traficar drogas foi alterada, tornando-se mais branda, pelo menos para aquele sujeito que seja primário, portador de bons antecedentes e que não se dedique às atividades criminosas nem integre organização criminosa (hipótese do tráfico privilegiado). Em outras palavras, dados um mesmo contexto (realidade econômica, social, educacional, cultural, etc.) e um mesmo estado motivacional (escassez de dinheiro/necessidade de auferir lucros), de acordo com modelo aqui exposto, haverá uma tendência de aumento no número de pessoas dispostas a iniciar a pratica o tráfico de drogas visando suprir suas necessidades.

Neste aspecto, cabe asseverar que não se vislumbra nenhuma mudança nas variáveis "contexto" e "estado motivacional" que justificasse a modificação da consequência punitiva, a não ser que se chegasse à conclusão que o aumento da frequência do padrão comportamental operante traficar drogas não fosse mais indesejável socialmente. Não houve alteração substancial da realidade social brasileira (contexto), tanto assim que o STF não aponta qualquer alteração estrutural. A situação econômica continua semelhante (talvez pior), o nível educacional de nossa população continua precário, a situação da saúde pública (um dos bens jurídicos protegidos pelo tráfico de drogas) continua ruim e assim por diante. Também não é possível afirmar profunda alteração no estado motivacional das pessoas que justificasse a verdadeira guinada no entendimento do STF. A maioria das pessoas continua sem acessos a serviços de saúde e educação de qualidade, bem como sem condições de consumir em quantidade suficiente para proporcionar a eles um bom padrão de vida, de tal maneira que a necessidade de aumentar a renda, ainda que por meio da prática de ilícitos, continua premente.

O risco de traficar drogas diminuiu ao passo que a consequências reforçadoras permaneceram inalteradas (possibilidade de aumentar a renda por meio do tráfico drogas), pois mantem-se um mercado consumidor apto a comprar a droga que é posta à venda. Assim, a decisão do Supremo Tribunal Federal não se sustenta quando submetida ao modelo analítico-comportamental. 
Poderia se supor que a Suprema Corte brasileira não esteja preocupada com as eventuais consequências sociais indesejáveis advindas do tráfico de drogas e que, por isso, resolveu abrandar as consequências punitivas da venda de drogas ilícitas. Mas, ainda assim, seria difícil encontrar embasamento científico para a decisão do STF.É que se o aumento da frequência de determinado padrão comportamental operante não é suficientemente preocupante, não haveria motivos para puni-lo. Nesse caso, o STF deveria ter descriminalizado a venda de drogas praticada por pessoa primária, portadora de bons antecedentes, desde que ela realizasse essa traficância sem se dedicar a outras atividades criminosas e sem integrar organização criminosa, se é que isso é mesmo possível.

Abrandar a consequência punitiva não vai mesmo diminuir a prática do tráfico, ao contrário, e o modelo analítico-comportamental nos mostra isso. Para citar um exemplo, com a Lei Federal no 11.343/2006, a mesma que instituiu o tráfico privilegiado, ocorreu o que o Supremo Tribunal Federal chamou de despenalização do consumo de drogas ${ }^{11}$, ou seja, a posse de droga para uso pessoal continua sendo crime, mas não é mais apena com pena restritiva de liberdade. Logo, a nova lei de tráfico abrandou a consequência punitiva do padrão comportamental operante consumir drogas ilícitas. O que ocorreu foi justamente um aumento no número de pessoas detidas na posse de entorpecentes para consumo. Para ilustrar essa realidade, citamos dados da Secretaria de Segurança Pública do Estado de São Paulo, que por ser o Estado com a maior população no país pode ser uma boa referência do que ocorre nacionalmente. A tabela abaixo mostra o número de pessoas detidas por porte e também por tráfico de drogas a cada ano.

\begin{tabular}{|c|c|c|}
\hline ANO & PORTE DE DROGA & TRÁFICO DE DROGA \\
\hline 2004 & 20.441 & 14.261 \\
\hline 2005 & 20.059 & 16.166 \\
\hline 2006 & 21.492 & 18.217 \\
\hline 2007 & 23.775 & 23.127 \\
\hline 2008 & 22.113 & 24.963 \\
\hline 2009 & 23.273 & 27.886 \\
\hline 2010 & 21.630 & 30.421 \\
\hline 2011 & 26.126 & 35.584 \\
\hline 2012 & 28.429 & 41.115 \\
\hline 2013 & 30.466 & 43.556 \\
\hline 2014 & 26.624 & 41.563 \\
\hline 2015 & 32.278 & 44.364 \\
\hline 2016 & 32.873 & 45.549 \\
\hline
\end{tabular}

Fonte: Secretaria de Segurança Pública do Estado de São Paulo

Como é possível perceber, a quantidade de pessoas flagradas com droga para uso pessoal aumentou ano

\footnotetext{
${ }^{11}$ RE 430105 QO, Relator: Min. SEPÚLVEDA PERTENCE, Primeira Turma, julgado em 13/02/2007, DJe-004 DIVULG $26-$ 04-2007 PUBLIC 27-04-2007 DJ 27-04-2007 PP-00069 EMENT VOL-02273-04 PP-00729 RB v. 19, n. 523, 2007, p. 17-21 RT v. 96, n. 863,2007 , p. $516-523$.
} 
a ano, sendo que entre 2006 (ano de criação da Lei Federal no 11.343/2006) e 2016 o aumento foi de 52, 95\%, ao passo que a população no Estado de São Paulo nesse mesmo período cresceu apenas $12.36 \%^{12}$. Os números são significativos, notadamente quando se tem em mente a "inelasticidade da demanda" ${ }^{13}$ no mercado de drogas ilícitas ${ }^{14}$, de tal modo que nem mesmo o aumento da oferta - representada na tabela pelo também aumento do número de traficantes de droga -, o que em regra leva a uma maior disputa no mercado e redução do preço das drogas, justificaria por si só o aumento do número de usuários. No mesmo sentido, o aumento do número de compradores faz com que aumente o número de pessoas dispostas a vender, o que fica nítido na tabela acima.

Se para o Supremo Tribunal Federal o combate à venda não é um bom caminho para solucionar o problema, a outra opção seria combater o consumo e, nesse sentido, a despenalização do uso não se mostrou uma medida eficiente. É importante ter em mente que a despenalização do uso de drogas promovida pela Lei Federal $n^{\circ} 11.343 / 2006$ não visou à diminuição do consumo, mas sim a implementação de uma nova política penal na qual o viciado deixa de ser tratado como criminoso e passa a ser tratado como um sujeito que necessita tratamento e até mesmo como mais uma vítima do tráfico. De todo modo, ainda que esse não fosse o intuito do legislador, a diminuição da repressão comprovadamente fez aumentar o número de usuários detidos pela polícia na posse de drogas.

Por outro lado, se para o Supremo Tribunal Federal o combate efetivo da venda de drogas não se mostrou uma boa política pública, o que o leva a acreditar que com um combate menos intenso, com o abrandamento da consequência punitiva, a questão seria mais bem resolvida? Se o combate efetivo e duro não é bom, a estratégia deveria ser a descriminalização, e não o simples abrandamento da punição.

Para o controle do padrão comportamental traficar drogas a decisão do Supremo Tribunal Federal não se sustenta quando submetida ao modelo analítico-comportamental e isso não é de difícil alcance, o que nos leva a crer que a preocupação do Supremo Tribunal Federal não era tanto com o tráfico de drogas em si. Se a diminuição do tráfico de drogas não era o objetivo maior de sua tomada de decisão, qual seria então o objetivo ou a preocupação da Corte Suprema brasileira? Como já aqui adiantado e como constou expressamente dos votos de alguns dos ministros do STF, a preocupação não era com o aumento da venda de drogas, mas sim com o

\footnotetext{
${ }^{12}$ De acordo com dados o Instituto Brasileiro de Geografia e Estatística - IBGE, no ano de 2006 o Estado de São Paulo possuía uma população de 39.824 .526 e no ano de 2016 a população era de 44.749 .699 habitantes.

${ }^{13}$ A elasticidade é uma medida de como os consumidores reagem às alterações nos preços dos produtos. O mercado de drogas é inelástico, pois, ainda que, por exemplo, ocorra uma significativa diminuição no preço da droga isso não acarretará um aumento correspondente e proporcional do número de usuários. Apesar do baixo valor da droga muitos continuarão sem consumi-la por fatores diversos, como riscos a saúde ou recriminação social, por exemplo.

${ }^{14} \mathrm{O}$ Assunto foi abortado em um famoso artigo, coordenado por Gary Backer, ganhador do Prêmio Nobel de Economia, no qual se mostra que os gastos do Estado para combater o consumo de drogas não geram a esperada diminuição na mesma proporção, BECKER, Gary; MURPHY, Kevin; GROSSMAN, Michel. The Market for Illicit Goods: The Case of Drugs. Journal of Economy, Chicago, vol. 114, 2006, p. 38-60.
} 
aumento do número de pessoas presas. O Supremo Tribunal Federal estava preocupado com o propalado superencarceramento. Vale dizer, ao verdadeiramente estabelecer uma regra jurídica no sentido de que o tráfico privilegiado não pode ser equiparado a crime hediondo, o STF pretende atingir uma meta social de diminuição do número de presos no país. Mais uma vez a análise comportamental se mostra útil para investigar se a regra jurídica estabelecida pelo Supremo Tribunal Federal é a mais adequada para atingir a meta social visada.

Antes de se passar à análise comportamental da regra jurídica estabelecida pelo STF tendo como norte sua meta social é importante relembrar algo aqui mencionado, qual seja, que no modelo analítico comportamental as regras jurídicas visam a uma alteração comportamental por meio do controle coercitivo de comportamentos politicamente considerados como prejudiciais à sobrevivência, reprodução e bem-estar da sociedade (AGUIAR, 2017, p 33). Esta se aqui admitindo a decisão do Supremo Tribunal Federal como sendo uma regra jurídica, pois permanece o caráter punitivo da conduta do tráfico de drogas privilegiado, ainda que a consequência punitiva tenha sido abrandada. De qualquer modo, se a regra jurídica visa evitar prejuízos à sobrevivência reprodução e bem-estar da sociedade já seria o caso de se perguntar o que atualmente é mais prejudicial à coletividade, se o aumento do número de presos ou o aumento do tráfico e do uso de drogas. O posicionamento do STF só é defensável se se entender que para a sociedade brasileira a diminuição do número de presos será mais benéfica, mesmo que isso leve ao aumento do padrão comportamental traficar drogas. Caso contrário, aqui já estaria encerrada a discussão, ante ao erro do Supremo Tribunal Federal na escolha da meta social a ser atingida (diminuição do número de presos versus diminuição do tráfico).

Para essa ponderação visando alcançar ao resultado mais benéfico para a coletividade seria importante até mesmo fazer uma diferenciação entre as diversas drogas que circulam no país, pelo menos entre as mais utilizadas. É que se pode concluir, por exemplo, que a venda e uso de uma determinada droga (o crack, por hipótese) causa prejuízos sociais de uma magnitude tal que o seu combate efetivo é mais benéfico, mesmo diante dos custos gerados pelo encarceramento daqueles que traficam tal droga. Já em relação a outra droga (a maconha ou o lança perfume) tal assertiva pode não se mostrar verdadeira. Nesse caso, o correto seria liberar as drogas cujo uso não repercute significativamente no ambiente social, tornando o encarceramento menos vantajoso para a sociedade e, por outro lado, concentrar forças no combate àquelas drogas cujo tráfico e uso causam consideráveis prejuízos à sobrevivência reprodução e bem-estar da sociedade, o que faz com que o custo social do encarceramento seja recompensado pela diminuição necessária do padrão comportamental traficar aquela droga. Entretanto, o Supremo Tribunal Federal não fez nenhuma diferenciação entre os tipos de entorpecentes, o que nos faz concluir que para aquele tribunal a diminuição do número de presos é prioridade (meta social) em relação 
combate ao tráfico de todas as drogas ${ }^{15}$.

Para que se possa prosseguir em nossa análise, vamos admitir que o Supremo Tribunal Federal agiu corretamente na escolha da meta social (redução do encarceramento), fazendo-o apenas para fins acadêmicos, sem que isso signifique verdadeiramente uma concordância. ${ }^{16}$

Pois bem, como premissa comportamental relevante para a adoção da regra jurídica é possível dizer que o Supremo Tribunal Federal adotou a que a não equiparação do tráfico privilegiado a crime hediondo contribuiria para a diminuição do número de presos.

Dando continuidade à análise comportamental da regra jurídica cabe questionar se essa premissa comportamental relevante é ou não verdadeira, sendo para isso importante separar as hipóteses de prisão definitiva e prisão temporária.

Quando se fala de preso definitivo, ou seja, aquele que já foi condenado com transito em julgado, a premissa comportamental relevante adotada pelo Supremo Tribunal Federal não se mostra verdadeira por um motivo muito simples, qual seja, o condenado por tráfico de drogas privilegiado na prática já não cumpria pena no regime fechado, de modo que não são os condenados definitivamente por tráfico privilegiado os responsáveis por ocupar as vagas disponíveis em nossos presídios.

De acordo com o artigo 33, caput, da Lei Federal no 11.343/2006 a pena do tráfico de drogas é de reclusão, de 5 (cinco) a 15 (quinze) anos e pagamento de 500 (quinhentos) a 1.500 (mil e quinhentos) diasmulta. Para que o tráfico seja privilegiado, de acordo com o $\$ 4^{\circ}$ do mesmo artigo 33 , o réu deve ser primário e portador de bons antecedentes, o que indica que a pena irá se aproximar do mínimo de 5 (cinco) anos. Sobre esse patamar 5 (cinco) anos ou um pouco mais que isso irá incidir a causa de diminuição de pena do tráfico privilegiado, a qual, também de acordo com o $\$ 4^{\circ}$ provocará uma redução de $(1 / 6)$ um sexto a $(2 / 3)$ dois terços da pena. No mesmo sentido, por ser o réu necessariamente primário e portador de bons antecedentes a redução tende a se aproximar do máximo (2/3), por ser ela mais benéfica ao réu. Em resumo, a realidade é que à pessoa que é condenada por tráfico de drogas privilegiado hoje no Brasil é aplicada uma pena menor do que 4 (quatro) anos. Assim, o condenado por tráfico privilegiado de drogas desde o início já terá direito ao cumprir sua pena no regime aberto (artigo 33, $\$ 11^{\circ}$, 'c', do Código Penal). Mas não é só isso, o condenado por tráfico privilegiado terá, nos termos do artigo 44 do Código Penal, direito à substituição de sua pena privativa de liberdade por penas restritivas de direito (prestação de serviço à comunidade e limitação de final de semana, por exemplo), de tal forma que ele jamais será encarcerado. Portanto, a premissa comportamental relevante de que a não equiparação

\footnotetext{
${ }^{15}$ Para uma discussão da importância de se considerar custos sociais na tomada de decisões veja Tabak (2015).

${ }^{16}$ A profunda discussão sobre qual meta social deve ser adotada, redução do número de presos ou redução máxima da venda e consumo de drogas envolve a análise de uma complexidade de questões, o que extrapola os objetivos do presente trabalho.
} 
do tráfico privilegiado contribuirá significativamente com a redução da massa carcerária não é verdadeira quando se trata de presos definitivos, pois quem é definitivamente condenado por tráfico de droga privilegiado, em regra, não fica preso. Em se tratando de prisão definitiva, a regra jurídica estabelecida pelo Supremo Tribunal Federal, ao ser submetida ao modelo analítico-comportamental, não se mostra apta a atingir satisfatoriamente a meta social, pois não há relação causal fundamental entre a condenação por tráfico privilegiado de drogas e o cumprimento de pena na prisão.

Discutidos os casos de prisão definitiva, resta analisar a veracidade da premissa comportamental relevante de que a não equiparação do tráfico privilegiado ao crime hediondo provocará significativa diminuição no número de presos provisórios, possibilitando a obtenção da meta social redução do superencarceramento.

O número de presos provisórios no Brasil realmente é significativo e, de acordo com dados levantados pelo Conselho Nacional de Justiça - CNJ - em janeiro de 2017, mais de um terço das pessoas presas no Brasil eram presos provisórios.

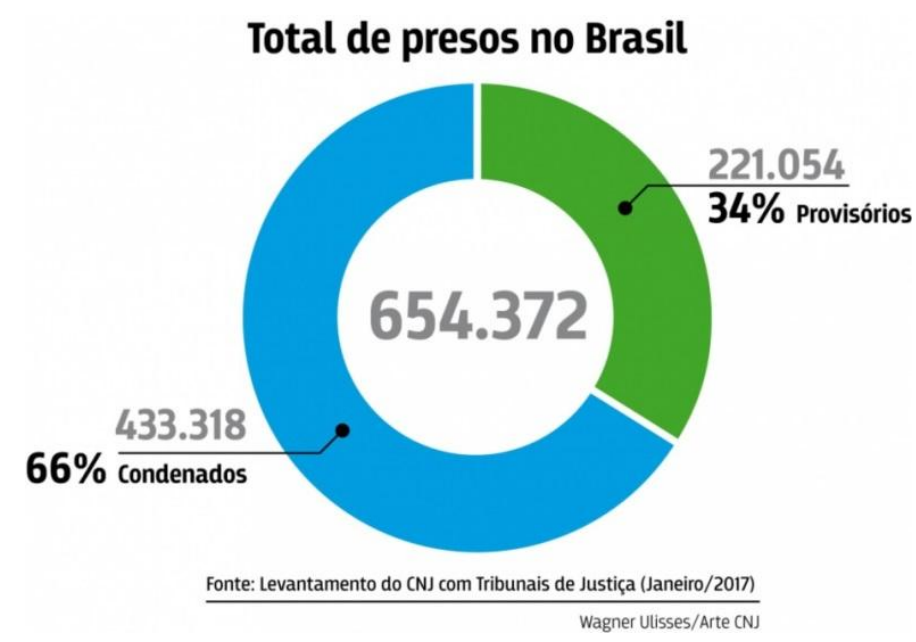

Em alguns Estados da Federação, como Sergipe, por exemplo, esse percentual passa dos 80\% e em Estados com grande quantidade de presos como Rio de Janeiro e Minas Gerais o percentual de presos provisórios ante o total da massa carcerária gira em torno dos $40 \%$. 
PERCENTUAL DE PRESOS PROVISÓRIOS EM RELAÇÃO AO TOTAL DE PRESOS POR UF

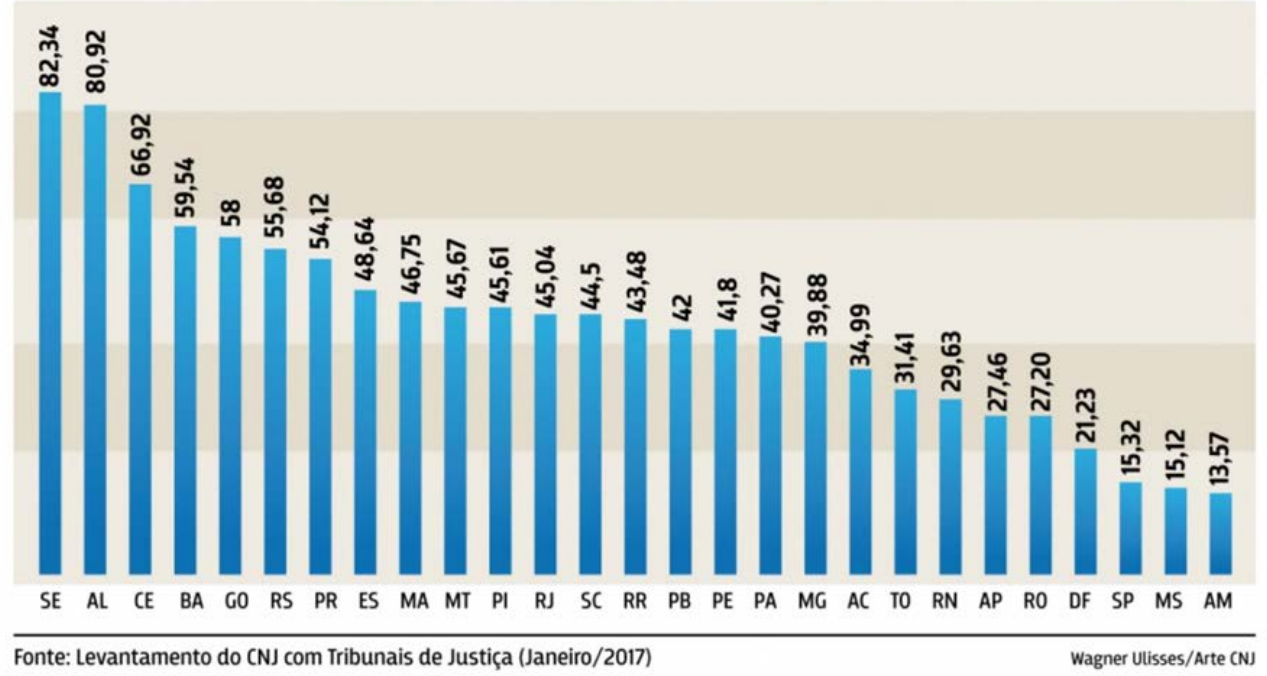

Os dados coletados pelo CNJ mostram que a questão envolvendo as prisões provisórias é relevante quando se discute eventual superencarceramento ou mesmo quaisquer outros problemas que envolvam a política penitenciária. Os dados mostram ainda que o impacto trazido ao sistema prisional pelos presos provisórios não se limita à quantidade deles que estão nos estabelecimentos prisionais, mas também o tempo em que eles permanecem presos, ou seja, o tempo que eles ocupam o limitado número de vagas disponíveis nos presídios nacionais.

Conforme demonstra a tabela abaixo com dados de janeiro de 2017, uma parcela considerável dos presos provisórios ficam encarcerados por mais de 180 (cento e oitenta dias). Minas Gerais é o Estado da Federação que possuía o maior número de presos provisoriamente há mais de cento e oitenta dias (18333), o que representava 69\% dos presos provisórios. Em São Paulo, Estado com uma grande massa carcerária, 49\% dos presos provisórios estavam encarcerados há mais de 180 dias. 


\section{NÚMERO DE PRESOS PROVISÓRIOS COM MAIS 180 DIAS DE CUSTÓDIA CAUTELAR POR UF}

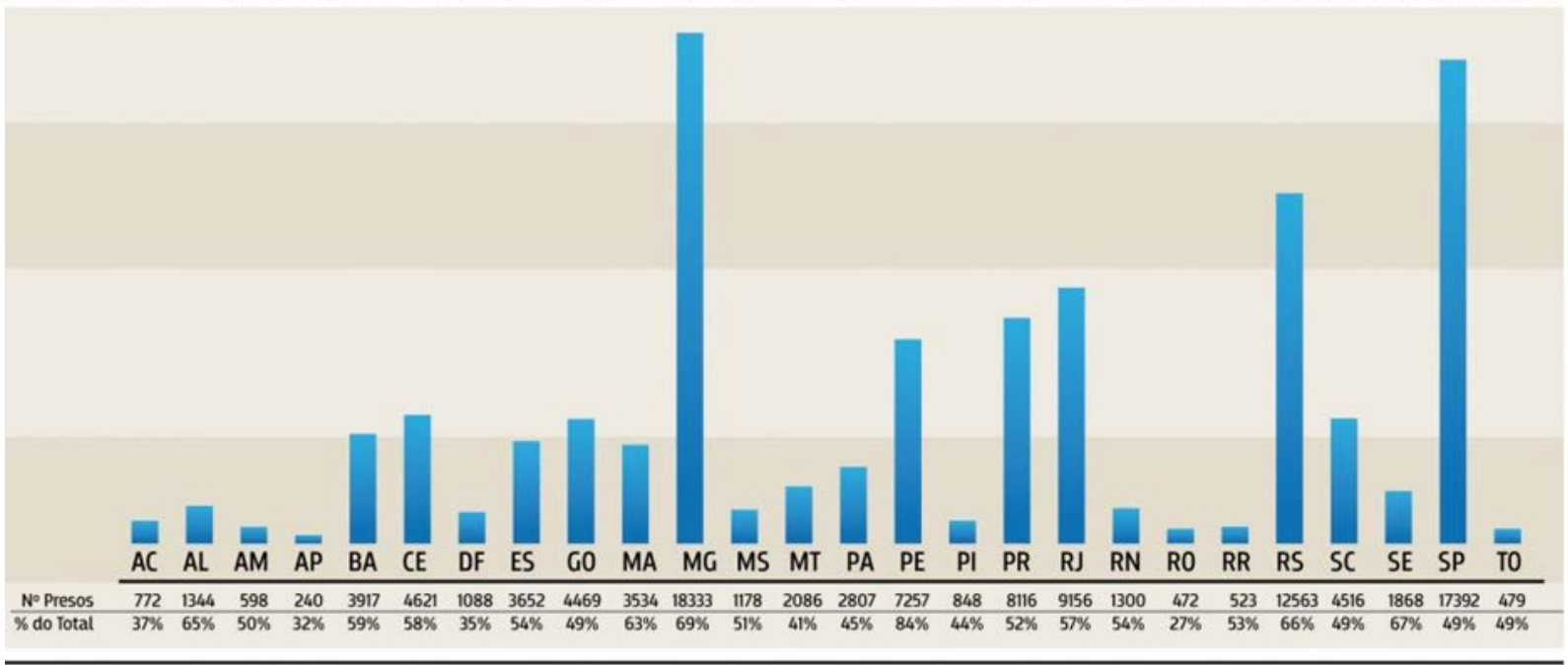

Fonte: Levantamento do CNJ com Tribunais de Justiça (Janeiro/2017)

Wagner Ulisses/Arte CN.

Se o número de presos provisórios é considerável, o número de presos provisoriamente pela imputação de terem cometido tráfico de drogas também o é. Os dados mostram que quase 1/3 (um terço) dos presos provisórios no Brasil eram acusados de cometerem tráfico de drogas (privilegiado ou não), de tal modo que o tráfico de drogas contribui de maneira importante para o número de presos provisórios.

\section{PERCENTUAL DE PRESOS PROVISÓRIOS POR TIPO DE CRIME PRATICADO}

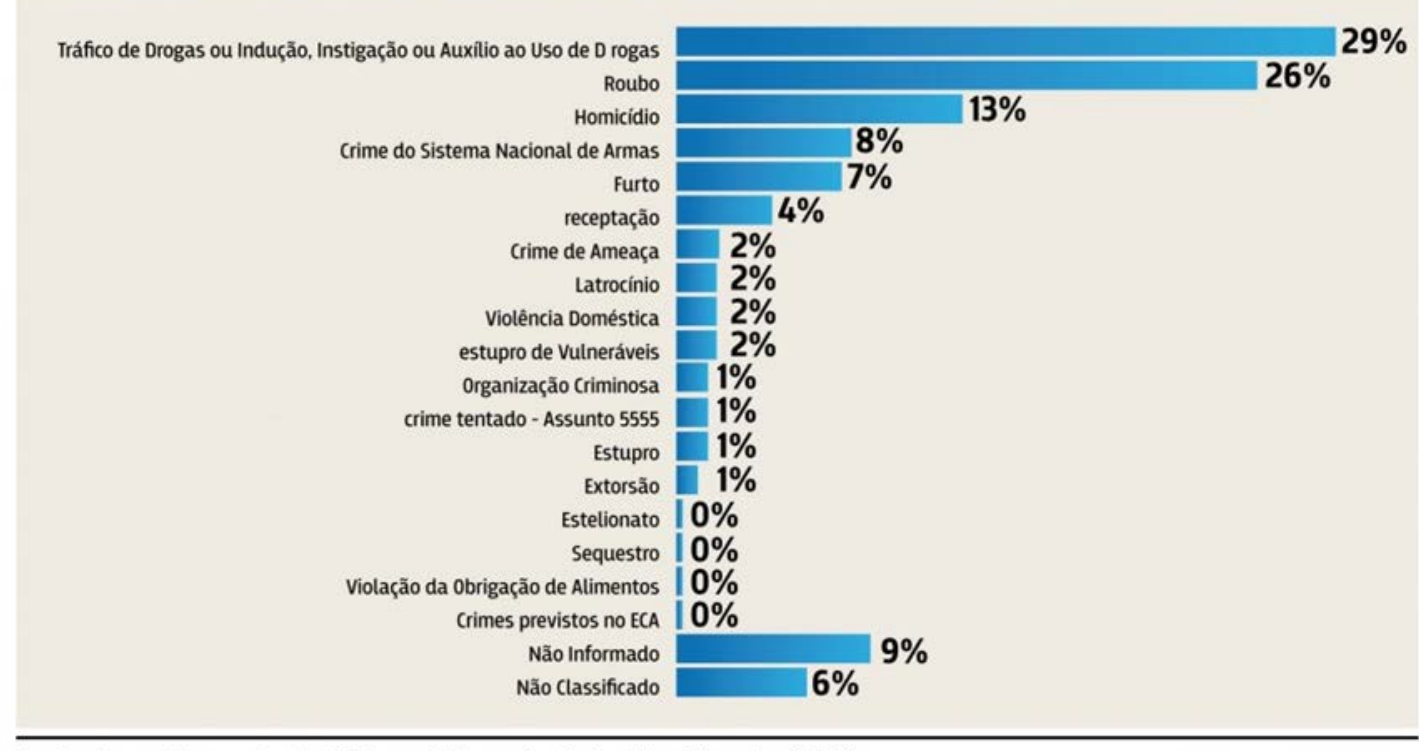

Fonte: Levantamento do CNJ com Tribunais de Justiça (Janeiro/2017)

Wagner Ulisses/Arte $\mathrm{C} N$ J

Como os dados não trazem uma divisão específica entre tráfico privilegiado e tráfico de drogas comum, para que a premissa comportamental relevante adotada pelo Supremo Tribunal Federal esteja correta é preciso 
admitir que uma parte considerável daquele contingente de $29 \%$ dos presos provisórios praticou tráfico privilegiado. Se só uma minoria for representada pelo tráfico privilegiado a premissa comportamental relevante já será incorreta, pois, nessa hipótese, o tráfico privilegiado não contribuiria relevantemente para o número de presos provisórios e para o encarceramento como um todo. É plenamente compreensível que os dados do CNJ não façam a diferenciação entre o número de presos provisórios pela prática do tráfico (comum) e o número de presos pela prática do tráfico privilegiado. Como será discutido mais à frente, a diferenciação entre o tráfico privilegiado e o tráfico comum demanda análise aprofundada do caso concreto, o que exige na maioria das vezes pelo menos o término da instrução processual, sendo que em alguns casos tal questão só é definitivamente decidida em grau de recurso. Assim, como estamos falando de presos provisórios estamos nos debruçando sobre casos em que ainda não há uma decisão definitiva (em muitos casos sequer uma sentença de primeiro grau de jurisdição), o que nos impede de classificar de maneira específica o crime pelo qual o indivíduo está preso cautelarmente, haja vista que esta definição ocorrerá em momento processual posterior.

Para fins acadêmicos vamos admitir que uma parcela significativa dos presos provisórios por tráfico de drogas tenha praticado tráfico privilegiado, o que é mesmo provável que aconteça.

Como visto anteriormente, se ao abrandar a punição do tráfico privilegiado haverá, de acordo com o modelo analítico-comportamental, uma tendência de aumento da frequência do tráfico privilegiado, é possível prever que a decisão do Supremo Tribunal Federal possui potencial para aumentar não só a quantidade de tráfico privilegiado, mas a própria quantidade de presos provisórios, uma vez que parcela dos réus respondem ao processo preso. Portanto, a regra jurídica estabelecida pela Suprema Corte, ao invés de atingir a meta social diminuição do número de presos, tende a aumentar o número desses presos, ainda que provisórios. Se de um lado a não equiparação a crimes hediondos leva a uma diminuição do tempo para progredir de pena (diminuição de $2 / 5$ para $1 / 6$, como explicado em tópico anterior), tal benefício é contraposto pelo provável aumento da rotatividade de presos, mais pessoas presas (provisoriamente) ainda que por menos tempo. Aliás, preso provisório, em regra, sequer progride de pena, pois seu encarceramento é baseado em medida cautelar. Pode ocorrer até mesmo de ser tamanho o aumento do número de presos provisórios que isso piore a situação carcerária, ou seja, de o aumento do número de presos provisórios suplantar a diminuição de presos trazida pela redução da quantidade de pena cumprida para a progressão de regime.

Por fim, se parte das pessoas que praticam tráfico de drogas privilegiado estão respondendo ao processo presas (presos provisórios) e sendo soltas quando condenadas em definitivo (inclusive com a substituição da pena privativa de liberdade por restritivas de direito) o problema parece estar na imediata qualificação da conduta, de modo a se estabelecer previamente se se trata de tráfico privilegiado ou comum. As nuanças e a complexidade do caso concreto podem mesmo dificultar a correta tipificação da conduta criminosa desde o início, pois o 
completo esclarecimento das circunstâncias fáticas por vezes demanda a colheita de robusta prova, o que exige esperar o término da instrução processual. Mas a regra de que o tráfico privilegiado não é hediondo não facilita em nada a correta identificação da conduta, permitido rapidamente a qualificação como tráfico privilegiado ou tráfico comum. Isso só ocorreria se o Supremo Tribunal Federal tivesse, a título de exemplo, adotado a regra de o tráfico dessa ou daquela determinada droga não ser hediondo. Ou, também, por exemplo, a regra de que a apreensão de droga até certa quantidade (até certo peso) é indicativo de que o tráfico é privilegiado, o que demonstraria desde logo que a prisão provisória é desnecessária, pois nem mesmo a condenação definitiva resultará em prisão.

Em resumo, a premissa de que a não equiparação do tráfico e drogas a crime hediondo contribuirá significativamente para a redução de presos provisórios não é verdadeira, pois o abrandamento da punição tende a aumentar a frequência do tráfico privilegiado e consequentemente o número de pessoas presas provisoriamente por tal conduta ilícita. Some-se a isso o fato de que a regra jurídica estabelecida pelo Supremo Tribunal Federal em nada contribui para a prévia identificação da conduta como sendo tráfico de drogas privilegiado ou como tráfico de drogas comum, o que parece ser fundamental para se evitar prisões provisórias desnecessárias.

5. Conclusão

O Supremo Tribunal Federal ao julgar o HC 118533/MS alterou entendimento que perdurava há uma década, desde a promulgação da Lei Federal no 11.343/2006, passando a entender que o tráfico de drogas privilegiado, decorrente da aplicação do $₫ 4^{\circ}$ do artigo 33 da Lei mencionada, não pode ser equiparado aos crimes hediondos.

Pretendeu-se aqui submeter este entendimento à análise comportamental do Direito, a qual se constitui em uma nova abordagem científica do Direito, que encontra fundamento em uma versão do behaviorismo radical de Skinner.

De acordo com o modelo analítico-comportamental a decisão do Supremo Tribunal Federal tem potencial para fazer aumentar o número de pessoas que adotam o tráfico de drogas privilegiado como padrão comportamental operante, ante o abrandamento das consequências (punição) de tal conduta.

Contudo, a preocupação maior do Supremo Tribunal Federal ao tomar tal decisão não era com o combate efetivo do tráfico de drogas, mas sim com o aumento do número de presos, com o que chamado superencarceramento.

Tomando a decisão do Supremo Tribunal Federal como sendo verdadeira regra jurídica, estabelecida com o intuito de obter a meta social de redução significativa do número de presos, buscou-se fazer a análise comportamental de tal regra.

Como conclusão, tem-se que a regra jurídica estabelecida pelo STF não será capaz de diminuir sensivelmente o problema da quantidade de presos, pois parte de uma premissa comportamental relevante falsa, 
haja vista que os condenados definitivamente por tráfico de drogas privilegiado já não cumpriam pena em regime fechado e a possibilidade de aumento do número de pessoas que praticam o tráfico privilegiado faz, consequentemente, aumentar o número de pessoas que são presas provisoriamente pela prática desse mesmo crime.

\title{
THE NON-EQUIPMENT OF PRIVILEGED DRUG TRAFFICKING TO HEXED CRIME: A BEHAVIORAL ANALYSIS
}

\begin{abstract}
The present legal article intends to make a behavioral analysis of the understanding of the Federal Supreme Court adopted in the judgment of HC 118533 that the so-called privileged traffic can not be equated with the heinous crimes, discussing scientifically whether or not the decision of the Supreme Court will contribute to the number of people arrested in the country.
\end{abstract}

Keywords: behavioral analysis - drug trafficking - heinous crime - imprisonment

\section{REFERENNCIAS BIBLIOGRÁFICAS}

AGUIAR, Julio Cesar de. O direito como sistema de contingências sociais. Revista da Faculdade de Direito da Universidade Federal de Goiás, vo. 37, n. 2, p. 164-196, 2013.

Teoria Analítico-Comportamental do Direito: uma abordagem científica do direito como sistema social funcionalmente especializado. Porto Alegre: Nuria Fabris, 2017.

BAUM, William. Compreendendo o behaviorismo: comportamento, cultura e evolução. Porto Alegre: Artmed, 2006.

BRASIL. Constituição, 1988.

Decreto 54.216, 1964 . 
Lei Federal 8.072, 1990.

Lei Federal 11.343, 2006.

BOBBIO, Norberto. Teoria do ordenamento jurídico. Apresentação de Tércio Sampaio Ferraz Júnior. Trad. Maria Celeste C. J. Santos. Revisão técnica de Cláudio De Cicco. 5.ed. Brasília: Universidade de Brasília, 1994.FELDENS, Luciano. Direitos fundamentais e Direito Penal: garantismo, deveres de proteção, princípio da proporcionalidade, jurisprudência constitucional penal, jurisprudência dos tribunais de direitos humanos. Porto Alegre: Livraria do Advogado, 2008.

CNJ - Conselho Nacional de Justiça. Levantamento de Presos no Brasil. Dados de Janeiro 2017. Disponível em $<$ http://www.cnj.jus.br/noticias/cnj/84371-levantamento-dos-presos-provisorios-do-pais-e-plano-de-acao-dostribunais>. Acessado em 12 set. de 2017.

CNJ - Conselho Nacional de Justiça. Novo diagnóstico de pessoas presas no Brasil. Dados de 2014. Disponível em < http://www.cnj.jus.br/images/imprensa/diagnostico de pessoas presas correcao.pdf $>$. Acessado em 12 set. de 2017.

HESSE, Konrad. A força normativa da Constituição. Porto Alegre: Sergio Antonio Fabris, 1991.

INSTITUTO Brasileiro de Geografia e Estatística. Projeção da População do Brasil por sexo e idade: 2000-2060. Disponível em <http://www.ibge.gov.br/home/estatistica/populacao/projecao_da_populacao/2013/default_tab.shtm>. Acessado em 15 set. 2017.

MARCÃO, Renato Flávio. Tóxicos: Lei n. 11.343, de 23 de agosto de 2006: Lei de drogas. 9. ed. reformulada, rev. e atual. de acordo com a Lei n. 12.850/2013 (organização criminosa). São Paulo: Saraiva, 2014.

RANGEL, Paulo. Lei de drogas: comentários penais e processuais. e. ed. rev, ampl. e atual. até dezembro de 2013. São Paulo: Atlas, 2014.

SECRETARIA de Segurança Pública do Estado de São Paulo. Estatística. Disponível em <http://www.ssp.sp.gov.br/Estatistica/Pesquisa.aspx>. Acessado em 15 set. 2017. 
SKINNER Frederick Burrhus. Science and human behavior. New York: Free Pass, 1953.

Selection by consequences. Science, vol. 213, n. 4507, pp 501-504.

Sobre o behaviorismo. São Paulo: Cultrix, 2006.

TABAK, Benjamin Miranda. A Análise Econômica do Direito - Proposições Legislativas e políticas públicas.

Revista de Informação Legislativa / Senado Federal, Subsecretaria de edições Técnicas - Ano 52, no 205, jan./mar. 2015.

TABAK Benjamin Miranda; AGUIAR Julio Cesar de. Análise Econômico-comportamental do direito: ideias básicas. Direito Economia e Comportamento Humano. Curitiba: CRV, 2016.

Trabalho enviado em 14 de junho de 2018

Aceito em 19 de setembro de 2018 